\title{
Study on Brand Communication Principle
}

\author{
Xueling Zhang \\ Eastern International Art College \\ Zhengzhou University of Light Industry \\ Zhengzhou, China 450002
}

\begin{abstract}
Brand communication is not only the feelings and evaluation of consumers, but also the result of conscious spreading by brand owner. Brand communication is to conduct constant communication with the target audiences including consumers under the overall framework of brand identity, taking the core value of corporate brand as principle through such communication ways as advertising, public relations, marketing, interpersonal relationship and so on, to promote specific brand, thus to establish brand image and promote market sales.
\end{abstract}

Keywords - brand; brand communication principle

\section{INTRODUCTION}

The word of "brand" is originated from the Old Norse "brandr" with original meaning of "branded with the mark", and latter, the meaning of it is extended to "mark a distinctive sign". Brand is the comprehensive evaluation and recognition of the consumers on the enterprise and the products manufactured by it, the excellent product quality, perfect after-sale service, good product image, great cultural value and excellent business management, and a kind of mutual trust with consumers established by enterprise operators and managers by investing considerable manpower, material and financial resources and even several generations' long term efforts.

\section{BRAND FEATURES}

Nowadays, all sectors of society are talking about brand. Enterprises hope to establish their own brand and develop it well, state has given a lot of support in terms of policy, and media are also spreading various brand concepts. It can be seen from the definition of brand easily that people's understanding of brand is deepening continuously, and then accept it and becoming the target audiences. This is the result of brand concept along with the perfection of market economy and the development of marketing. No matter how the brand is extended, its basic connotation contains the following four features:

Excludability: Brand is a kind of name, term, mark, symbol or pattern, or their mutual combination. The original purpose of it is to make people remember a certain product or enterprise by virtue of a form that is easy to be remembered. Enterprise applies to relevant departments for brand image registration through legal procedures, thus it becomes the product mark that we all know, and the enterprise has exclusive right which is granted by law, making its products different from that of its competitors, which is exclusive. For example, upon registration of the brand of "Haier", it becomes an exclusive name, and other enterprises' using, counterfeit and falsification without Haier Company's authority will be an infringement act and illegal act, which shall be hold accountable by law.

Informativity: Informativity refers to the essential means of media communicator to conduct necessary impression management to brand image, so as to regulate the relationship between communicator and consumers, thus to ensure communication effects. Brand owner may gain profits by virtue of brand advantage, and expand continuously by taking advantage of market exploration, image expansion and capital internal storage of brand. Therefore, the brand value can be seen. Such value is not like physical assets that are expressed by material, but it may enable enterprise's intangible assets to increase rapidly, and be traded in the market as commodities.

Sociability: Actually it is a kind of communication management, and the brand maintenance conducted by merchants for economic benefits. The social function of brand has accelerated consumers' purchase decision process, meanwhile, it is convenient for consumers to make product recognition. As the saying goes that "goods rely on skillful publicity". And the realization of skillful publicity of commodities needs the social function of brand. Through the sociability of brand, a relationship with mutual understanding can be established between enterprise or products marketing and consumers. And such relationship is long lasting and stable, which will win consumers long lasting preference and loyalty.

Responsibility: Brand vitality will be disturbed by market environment, and be influenced by social environment and interrupted by political environment. In selecting goods among large quantity of similar products, in addition to consider the quality of the product itself and service value, consumers shall also consider the value of the product itself without doubt. It can be said that this is the reflection of enterprise's sense of responsibility in terms of brand image. Once the brand responsibility is established, no matter how severer the external environment, such sense of trust formed mentally by consumers will be relatively stable.

\section{BRAND COMMUNICATION PRINCIPLE}

Brand communication is to meet consumers' demands by enterprises, which can effectively cultivate consumers' trust, 
and is a flag hold high by entrepreneurs. Communication plays an important role in shaping of brand, and meanwhile, it is a main way to shape a brand.

The so-called brand communication is to continuously communicate with targeted audiences including consumers through advertising, public relations, marketing, interpersonal and other means of communication, with the core values of corporate brand as principle under the overall framework of brand recognition, to promote specific brand, so as to establish a brand image, thus to promote marketing.

In brief, brand communication is a process of information control and utilization through a variety of new and traditional communication means. In this process, a key factor for brand communication success lies in how to use the controllable communication resources; no matter the targeted consumers, or those who will not purchase directly but play a role of decision-making against other consumers, are the important objects of brand communication. Through brand communication, the ultimate aim is to increase brand influence, reputation, trust, recognition, association as well as brand loyalty and other brand equity including unique assets, thereby increasing the target group.

As an indispensable and important component for brand operation, or the form of high-level performance of intense competition in the market, and in today's highly competitive market economy, brand communication can be described as a core way for creating strong brand in the era of brand competition. For brand communication, the most important mode of communication is advertising. Advertising refers to the campaign against target consumers through various media of advertising business sector delegated by brand owners. Such campaign includes brand names, logos, positioning, and personality etc. Advertising is a commercial activity which shall be paid, which sells the planning and creativity about its brand communication. It can be said that in today's era, the media industry is highly developed, and film, television, radio, Internet, newspapers and magazines are ubiquitous, filling every aspect of life, which means advertising is ubiquitous. Advertising shows different brands as well as the advantages and uniqueness of the products for sale with enforceablility on audiences in various media, and sharply raises the issues concern by consumers, in order to attract attention and interest. Just for that reason, advertising has become the main form of brand communication.

In addition to such surface information as name, pattern, color, packaging and others, brand also contains such deep connotative information as "product characteristics", "benefits and service commitment", "brand recognition" and "brand association". Therefore, in addition to advertising, brand communication also includes products, brand names, trademarks and logos, brand characteristic and other factors. Product is the core strength of a brand, and the primary factor in brand communication. Brand communication just shows its uniqueness through the products and services initially; only the product is accepted by consumers, can the brand be recognized. Brand communication is not merely a mark for spreading products or services, but to inject some unique characteristics to the product or service, to increase added value. Brand names usually refers to its meaning no matter from subjective or objective point of view, thus to convey some features of the brand exclusively. Brand visual identity is the aggregation of various factors' images that exist in people's mind, and the fixed feature representation description used by many brands for long period of time. And such particular representation represents the brand itself to a certain degree, becoming a channel of communication with consumers. Its unique geographical resources have contributed to the unique advantage of brand, and some brands will establish its own characteristics from the aspect of geographical origin, which is the result of their own choice. For instance, some products will specify the geographical features, such as the Italian leather goods and French perfume which are like specialty, so their place of origin is indispensable for communication. Of course, some companies hope to create the concept of the Earth Family because of international communication or other reasons, and they will deliberately avoid geographical characteristics, so as not to affect their brand communication because of place of origin.

Brand communication has the following characteristics:

- Aggregation. This refers to aggregation of information. The information content of brand surface factors described by Philip Kotler such as name, pattern, color, packaging etc. is still limited, but such deep factors of brand such as "product characteristics", "benefits and services commitment", "brand recognition" and "brand association" contains abundant information. Static brand information constitutes a source of brand communication, and brand dynamism will determine the information aggregation of brand communication itself.

- Objectivity. This refers to objectivity of target audiences. As one of the communication in various communications, the brand communication' objects can only be consumers, which are its audiences. From the perspective of marketing, although the target consumers are most concerned by brand manager, the brand impresses consumers, and consumers promote "sales", and then to consume, is the most obvious logic; but from the perspective of communication, the target audiences are most concerned by brand communicators, the audiences are impressed by brands, thus to produce all kinds of behavior conducive to the brand, which will not only drive sales directly, but also may lead to a variety of indirect behavior, to conduct secondary brand communication intentionally or unintentionally, so that the potential consumers may turn into identifying consumers. Judging from this direction, the clear correspondence of brand communication is only the audiences. Only in the case of a clear target audience, can the audiences' awareness that exist in communication be reflected, can the audience's acceptance demand be met. Thus we can say that the corresponding brand communication is successful. 
- Diversity. This refers to media diversity. In today's revolutionary change of communication technologies, the birth of new media and newborn of traditional media will create vigorous vitality jointly, which will inevitably create a new pattern of diversified media. MacLuhan, a Canadian expert in communication, once said that "medium is message", that is to say, media technology often determines the message itself that is communicated. For example, the television media has spread much more information than newspapers and radio, and network media has spread the information including all the media messages. The diversified development of media has provided unprecedented good opportunity for brand communication. After all, it makes brand communication more effective; of course, such vigorous vitality also provides new challenges and opportunities to diversified integration of media application.

\section{BRAND COMMUNICATION MEDIA}

The connotation of brand communication determines the diversity of brand media. The real business communication practice tells us that in today's era of information explosion, the success of a brand to enter in the minds of consumers, and to achieve relatively mutual loyalty, or to occupy a place in their mind, and play a leading role at the time of its purchase, it can be said that, the single form of advertising for brand communication media is far from able to meet the requirements, or that it has already outdated.

Overall, new media is the new forms of media relative to the newspapers, radio, television and other traditional media, which transmits through the Internet (including broadband local area network), wireless communication network, satellite and other channels using digital network communication technology, and takes digital televisions, computer Internet, mobile phones and other display equipment as the terminal, providing information and services to audiences. Currently, digital new media includes: IPTV, mobile TV, blog, podcasts, search engines, instant messaging, and mobile phones. Depending on different display terminals, the new digital media can be divided into cable digital TV, IPTV, bus mobile TV, building television and others, taking TV set as the display terminal; websites, search engines, blog, instant messaging, podcasts etc. taking computer as display terminal; communication information and mobile TV taking mobile phones and other portable electronic equipment as the terminal.

\section{REFERENCES}

[1] James.E.Gruning. Public Relations is a Kind of Communication Management[M]. Translated by Guo Huimin. Journal of International Communication. 1998, 71

[2] Al Ries, Jack Trout. Advertising Psychological Strategy: Brand Positioning $[\mathrm{M}]$. Translated by Liu Zhiyi. Chinese Friendship Publishing Company, 1999, 30

[3] Meng Jian. Theoretical Explanation of Visual Cultural Communication[M]. Fudan University Press, 2005
[4] Yu Mingyang, Zhu Jida, Xiao Junsong. Brand Communication. [M]. Shanghai Jiao Tong University Press, 2005, 3. 